\title{
A Carbazole-Functionalized Porous Aromatic Framework for Enhancing Volatile Iodine Capture via Lewis Electron Pairing
}

\author{
Zhuojun Yan ${ }^{1}$, Bo Cui ${ }^{1}$, Ting Zhao ${ }^{2}$, Yifu Luo ${ }^{2}{ }^{\mathbb{D}}$, Hongcui Zhang ${ }^{1}$, Jialin Xie ${ }^{1}, \mathrm{Na} \mathrm{Li}^{1}$, Naishun Bu ${ }^{2, *(\mathbb{D},}$ \\ Ye Yuan ${ }^{3, *}$ and Lixin Xia ${ }^{1,4, *}$ \\ 1 College of Chemistry, Liaoning University, Shenyang 110036, China; zjyan@lnu.edu.cn (Z.Y.); \\ cuibo2019@163.com (B.C.); zhanghongcui2021@126.com (H.Z.); xj1810888632@163.com (J.X.); \\ linaa627@163.com (N.L.) \\ 2 School of Environmental Science, Liaoning University, Shenyang 110036, China; \\ zhaot17865818271@163.com (T.Z.); royjacklyf@126.com (Y.L.) \\ 3 Key Laboratory of Polyoxometalate and Reticular Material Chemistry of Ministry of Education, \\ Faculty of Chemistry, Northeast Normal University, Changchun 130024, China \\ 4 Yingkou Institute of Technology, Yingkou 115014, China \\ * Correspondence: bunaishun@Inu.edu.cn (N.B.); Yuany101@nenu.edu.cn (Y.Y.); lixinxia@lnu.edu.cn (L.X.)
}

\section{check for}

updates

Citation: Yan, Z.; Cui, B.; Zhao, T.; Luo, Y.; Zhang, H.; Xie, J.; Li, N.; Bu, N.; Yuan, Y.; Xia, L. A CarbazoleFunctionalized Porous Aromatic Framework for Enhancing Volatile Iodine Capture via Lewis Electron Pairing. Molecules 2021, 26, 5263. https://doi.org/10.3390/ molecules 26175263

\section{Academic Editor:}

Constantina Papatriantafyllopoulou

Received: 9 August 2021

Accepted: 27 August 2021

Published: 30 August 2021

Publisher's Note: MDPI stays neutral with regard to jurisdictional claims in published maps and institutional affiliations.

Copyright: (c) 2021 by the authors. Licensee MDPI, Basel, Switzerland. This article is an open access article distributed under the terms and conditions of the Creative Commons Attribution (CC BY) license (https:// creativecommons.org/licenses/by/ $4.0 /)$.

\begin{abstract}
Nitrogen-rich porous networks with additional polarity and basicity may serve as effective adsorbents for the Lewis electron pairing of iodine molecules. Herein a carbazole-functionalized porous aromatic framework (PAF) was synthesized through a Sonogashira-Hagihara cross-coupling polymerization of 1,3,5-triethynylbenzene and 2,7-dibromocarbazole building monomers. The resulting solid with a high nitrogen content incorporated the Lewis electron pairing effect into a $\pi$-conjugated nano-cavity, leading to an ultrahigh binding capability for iodine molecules. The iodine uptake per specific surface area was $\sim 8 \mathrm{mg} \mathrm{m}^{-2}$ which achieved the highest level among all reported $\mathrm{I}_{2}$ adsorbents, surpassing that of the pure biphenyl-based PAF sample by ca. 30 times. Our study illustrated a new possibility for introducing electron-rich building units into the design and synthesis of porous adsorbents for effective capture and removal of volatile iodine from nuclear waste and leakage.
\end{abstract}

Keywords: iodine capture; porous aromatic framework; Lewis electron; pairing effect; SonogashiraHagihara cross-coupling

\section{Introduction}

To overcome the energy shortages and environmental concerns originated from fossil fuels, nuclear power, the only mature technology, is considered a possible approach for providing electricity on a large scale with little greenhouse gases emission [1]. However, the treatment of nuclear waste and the emergency response for nuclear leakage, cause consternation in the increasing development of the nuclear industry [2]. The ${ }^{129} \mathrm{I}$ and ${ }^{131} \mathrm{I}$ atoms originated from the uranium fission are the two main ingredients of nuclear waste, especially ${ }^{129} \mathrm{I}$, which has an ultra-long radioactive half-life $\left(\mathrm{t}_{1 / 2}=15.7 \times 10^{6}\right.$ years $)[3,4]$. Because the enrichment and toxic effects in organisms, effective methods for the capture and removal of radiological iodine aroused strong concerns. To date, several strategies have been proposed, including dry dedusting [5,6], chemical precipitation [7], and physical adsorption [8-10]. Among them, the physical adsorption method has specific advantages of high adsorption efficiency, low cost, simple operation, and high recyclability [11,12].

Porous aromatic frameworks (PAFs) composed of covalently bonded light atoms $(\mathrm{H}, \mathrm{B}, \mathrm{C}, \mathrm{N}$, and $\mathrm{O})$, have superb thermal and chemical stability, high surface area, and tunable pore size, which make them ideal candidates for iodine capture from the nuclear waste stream containing volatile iodine radionuclides [13-16]. In the past few decades, PAF solids with tunable pore properties including surface area, volume, and size distribution were demonstrated to play important roles for the physical adsorption for guest 
molecules [17-20]. However, pure carbon-based PAFs with a micropore cavity do not show an excellent capacity and fast kinetics for $\mathrm{I}_{2}$ matter adsorption. For instance, PAF- 1 with an exceptionally high surface area $\left(5600 \mathrm{~m}^{2} \mathrm{~g}^{-1}\right)$ and micropore volume $\left(0.89 \mathrm{~cm}^{3} \mathrm{~g}^{-1}\right)$ exhibits a low iodine vapor capture capability with $186 \mathrm{wt} \%$ at $298 \mathrm{~K}$ per $40 \mathrm{~Pa}$ [21]. It is obvious that the adsorption capacity of the adsorbent for iodine is not only related to the surface area and pore size, but the effective adsorption sites on the accessible surface may possess a more important role to interact with volatile iodine gases. A detailed investigation should be conducted to reveal the relationship between the chemical features of PAFs and iodine molecules, which provides significant advantages and opportunities of PAFs for the development of next-generation porous adsorptions.

Based on the polarization effect, active sites transform the speciation of iodine molecules into multiple oxidation states $(-1,0,+1,+3,+5$, and +7$)$, primarily as molecular iodine $\left(\mathrm{I}_{2}\right)$, iodide $\left(\mathrm{I}^{-}\right)$, iodate, or organic iodine (org-I) [22-25]. A nitrogenous fragment possesses lone pair electrons, thereby revealing highly negative charge to enhance the binding affinity for the polarizable electron cloud of $\mathrm{I}_{2}$ molecules [26]. Herein, 2,7-dibromocarbazole was adopted as the functional building monomer to prepare a carbazole-containing PAF network through a one-step Sonogashira-Hagihara coupling reaction. Consequently, the resulting PAF sample with the electron-rich system exhibits an outstanding performance for the capture of a volatile iodine with an uptake of $2.10 \mathrm{~g} \mathrm{~g}^{-1}$. The results of this study provide useful guidance for the development of new porous adsorbents for the removal of radioactive iodine.

\section{Results and Discussion}

LNU-13 was synthesized through the Sonogashira-Hagihara coupling of 2,7-dibromocarbazole and 1,3,5-triethynylbenzene (Figure 1a). As determined by the Fourier transform infrared spectroscopy (FTIR, Figure 2a), the C-Br stretching vibration of 2,7-dibromocarbazole at $495 \mathrm{~cm}^{-1}$ and the $\mathrm{C}-\mathrm{H}$ stretching vibration of the terminal alkyne (1,3,5-triethynylbenzene) at $3270 \mathrm{~cm}^{-1}$ disappeared from the IR spectrum of LNU-13, verifying the completeness of the Sonogashira-Hagihara coupling reaction. The structural integrity of LNU-13 was further confirmed by ${ }^{13} \mathrm{C}$ NMR (Figure $2 b$ ). The main peaks observed in the range of $120-150 \mathrm{ppm}$ were attributed to the substituted carbon of the aromatic ring connected to the benzene ring; and the resonance around $90 \mathrm{ppm}$ was assigned to the carbons originated from the $-\mathrm{C} \equiv \mathrm{C}-$ group.

a
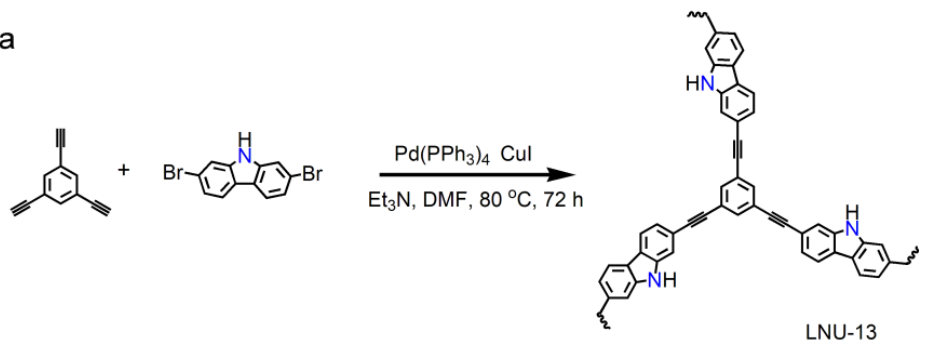

b
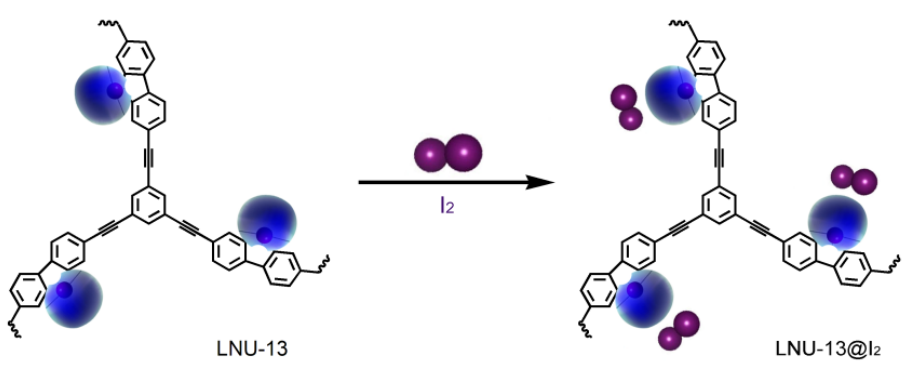

Figure 1. (a) Synthesis of LNU-13 polymer; (b) schematic diagram of PAF solid for $\mathrm{I}_{2}$ sorption. 
a

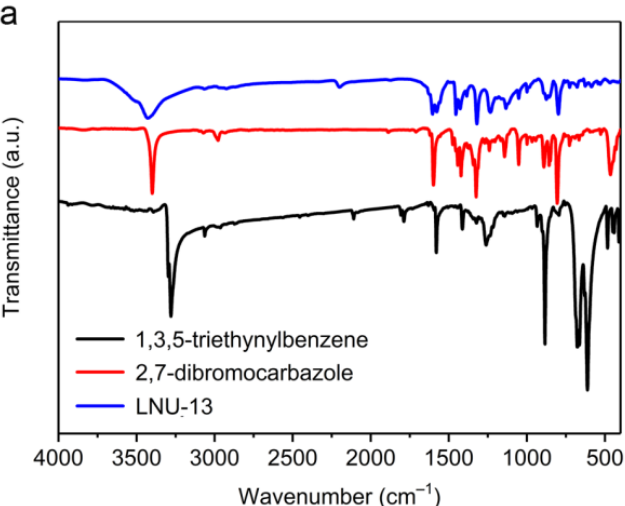

C
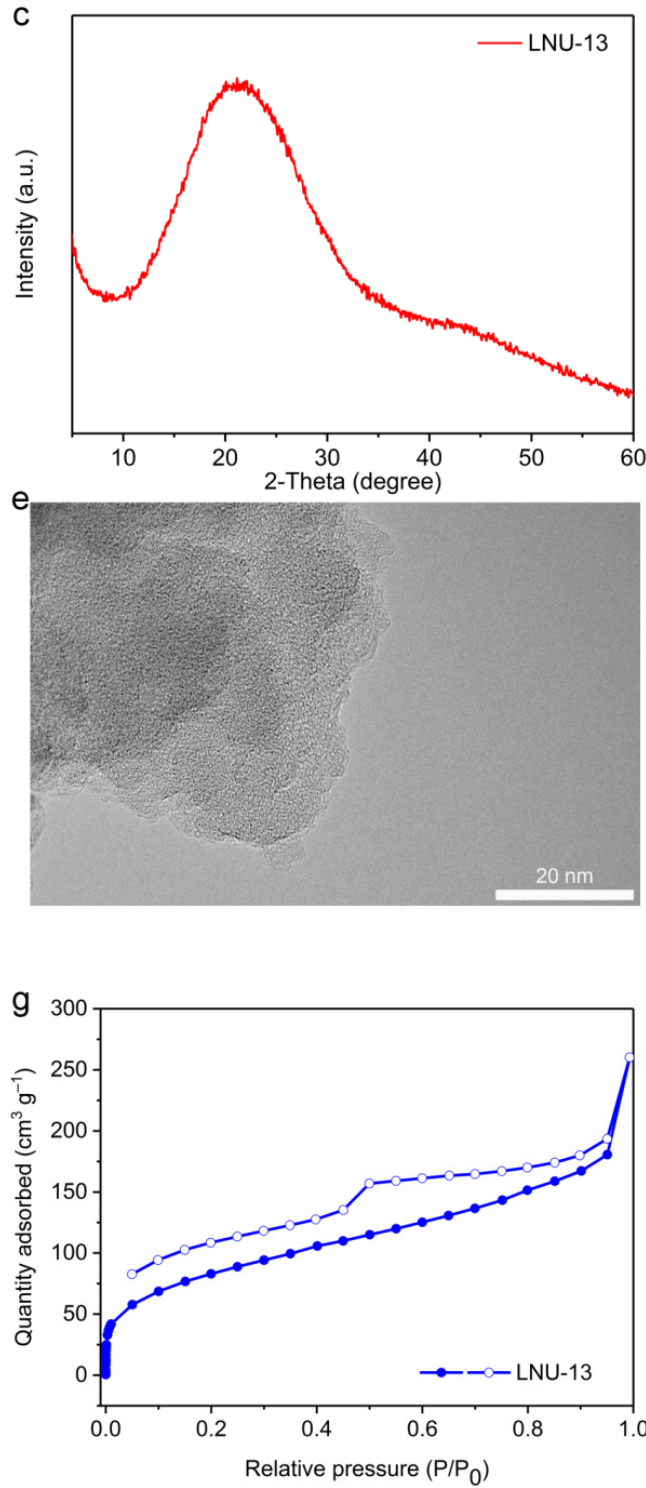
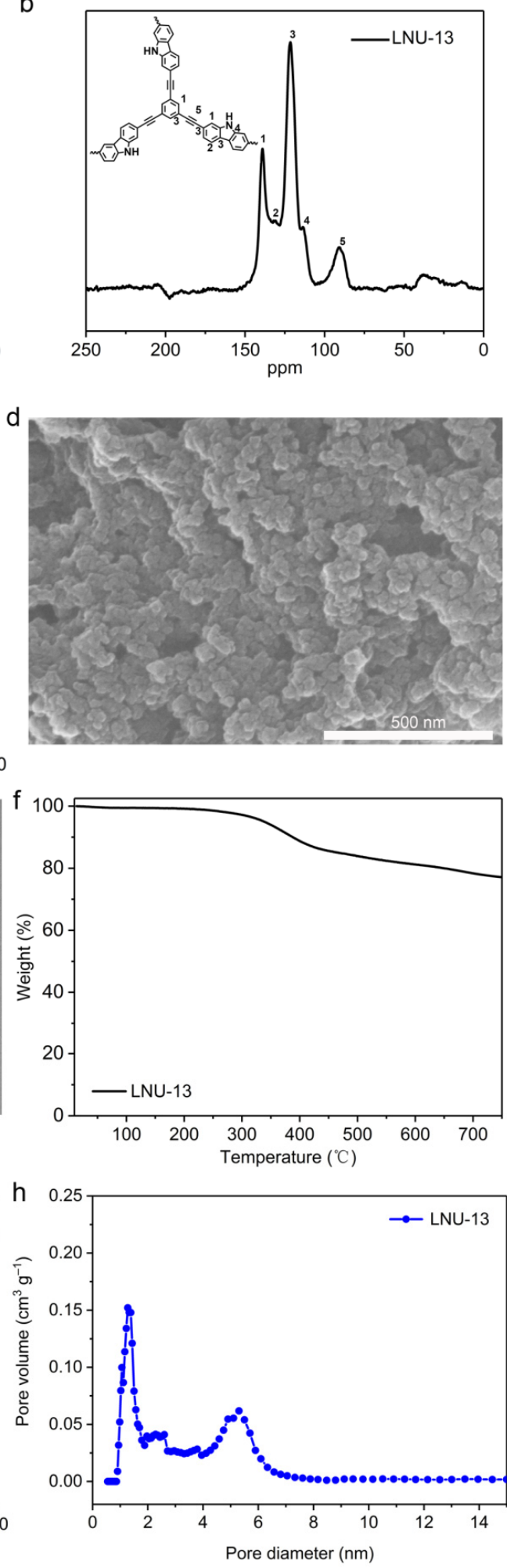

Figure 2. (a) FTIR spectra of 2,7-dibromocarbazole, 1,3,5-triethynylbenzene, and LNU-13; (b) solidstate ${ }^{13} \mathrm{C}$ NMR spectrum of LUN-13; (c) powder X-ray diffraction pattern of LNU-13. (d) SEM image of LNU-13; (e)TEM image of LNU-13; (f) TGA plot of LNU-13 at $\mathrm{N}_{2}$ condition with a ramp rate of $5{ }^{\circ} \mathrm{C} \mathrm{min}^{-1} ;$ (g) $\mathrm{N}_{2}$ adsorption-desorption isotherm of LNU-13; (h) pore size distribution of LNU-13. 
Powder X-ray diffraction (XRD) pattern of LNU-13 shows a characteristic broad peak, indicating they are amorphous in nature (Figure 2c). It seems that the formation of the stacked layer structure by the ordered connection among the building blocks is otherwise difficult $[13,27]$. Scanning electron microscopy (SEM) analysis demonstrated the stacked spherical structures of LNU-13, as shown in Figure 2d. Transmission electron microscopy (TEM) clearly confirmed the amorphous structure of LNU-13 (Figure 2e). As illustrated by thermogravimetric analysis (TGA, Figure 2f), the LNU-13 material begins to degrade at $350{ }^{\circ} \mathrm{C}$ and the weight loss is about $20 \%$ at $750{ }^{\circ} \mathrm{C}$ under a purified nitrogen atmosphere, indicating that LNU-13 possesses good thermal stability. All the results demonstrate that LNU-13 retains its intact skeleton under a variety of harsh conditions.

The porosity of the resulting PAF material was probed using $\mathrm{N}_{2}$ adsorption-desorption isotherms at $77 \mathrm{~K}$ up to 1 bar. The adsorption curve combined the features of type-I and type-IV adsorption isotherms, indicating the co-existence of a micro- and meso-pore system (Figure 2g). The BET surface area of LNU-13 was determined to be $255 \mathrm{~m}^{2} \mathrm{~g}^{-1}$. LNU-13 possessed wide pore size distribution in the range of 1-6 nm calculated using a nonlocalized DFT (NL-DFT) (Figure 2h). This hierarchical porous structure made the PAF solid an excellent scaffold for the access of the $\mathrm{I}_{2}$ guest into the internal space of LNU particle [28,29].

The iodine uptake measurement of LUN-13 was conducted by placing the PAF powder into a sealed vessel filled with iodine vapor at $348 \mathrm{~K}$ under normal atmosphere. As shown in Figure 3a, the iodine adsorption capacity increased significantly with the prolonging of the contact time. In the first $5 \mathrm{~h}$, the adsorption capacity of LNU-13 was very fast with a value of $1.75 \mathrm{~g} \mathrm{~g}^{-1}$. No further change in iodine loading was observed after $48 \mathrm{~h}$ exposure, indicating that LNU-13 was basically saturated $\left(2.10 \mathrm{~g} \mathrm{~g}^{-1}\right)$. A significant color change in the powder from brown to black was observed (Figure 3a inset). Calculated by the BET surface area $\left(255 \mathrm{~m}^{2} \mathrm{~g}^{-1}\right)$, the iodine uptake per specific surface area was $\sim 8 \mathrm{mg} \mathrm{m}^{-2}$ which achieved the highest level among silver-containing zeolite [30], metalorganic frameworks (MOFs), and conjugated microporous polymers (CMPs), etc., reported by the same adsorption method, surpassing that of PAF-1 by ca. 30 times (Figure 4). Moreover, it also has a certain competitiveness compared with other forms of adsorbent, such as carbon foam, fiber adsorbent, carbon cloth, aerogel, etc., including BN foam $\left(2.12 \mathrm{~g} \mathrm{~g}^{-1}\right)$ [31], PE/PP-g-PNVP fibers $\left(1.2378 \mathrm{~g} \mathrm{~g}^{-1}\right)$ [32], C60-CC-PNP $\left(2.4 \mathrm{~g} \mathrm{~g}^{-1}\right)$ [33], CC-PNP $\left(1.02 \mathrm{~g} \mathrm{~g}^{-1}\right)$ [33], ENTDAT dried gel $\left(1.8 \mathrm{~g} \mathrm{~g}^{-1}\right)$ [34], G-TP5 $\left(0.67 \mathrm{~g} \mathrm{~g}^{-1}\right)$ [35] and G-TP6 $\left(0.58 \mathrm{~g} \mathrm{~g}^{-1}\right)$ [35].

The adsorption mechanism of iodine vapor in LNU-13 was studied through PXRD, Raman, and FT-IR spectroscopy. Curve-fitting for the $\mathrm{I}_{2}$ adsorption isotherm was based on pseudo-second-order kinetics (Figure 3b), a high correlation coefficient $\left(R^{2}=0.99993\right)$ suggested the chemical adsorption process of LNU-13. As shown in Figure 5a, there were no characteristic peaks of $\mathrm{I}_{2}$ crystal diffraction peaks observed in the iodine-loaded LNU-13 (LNU-13@I $\mathrm{I}_{2}$ ). This phenomenon proved the monodispersed iodine species in the form of molecular or ionic states in the PAF architecture [27]. Raman spectroscopy of LNU-13@ $\mathrm{I}_{2}$ presented a series of bands centered at 110 and $170 \mathrm{~cm}^{-1}$ (Figure 5b). The characteristic bands in the region of $100-120 \mathrm{~cm}^{-1}$ were assigned to the symmetric stretching of the $\mathrm{I}^{3-}$ species, while the band located at $170 \mathrm{~cm}^{-1}$ was ascribed to the higher polyiodide anions, i.e., $\mathrm{I}^{5-}[36,37]$. Comparing the FTIR spectra of pristine LNU-13 and LNU-13@ $\mathrm{I}_{2}$ (Figure 5c,d), the aromatic rings were centered at $1555 \mathrm{~cm}^{-1}$ in LNU-13 vs. $1612 \mathrm{~cm}^{-1}$ in $\mathrm{I}_{2} @ \mathrm{LNU}-13$. A similar shift was also observed for the band assigned to $v_{\mathrm{C}-\mathrm{N}}(\mathrm{str})$ bond vibration (1234 $\mathrm{cm}^{-1}$ for LNU-13 and $1262 \mathrm{~cm}^{-1}$ for $\mathrm{I}_{2} @ \mathrm{LNU}-13$ ). In addition, the peak at $731 \mathrm{~cm}^{-1}$ belonged to the characteristic signal for iodine molecules. All these results indicate that the lone pair electron of the carbazole nitrogen polarizes the iodine molecule into an ionic state, and then achieves the excellent adsorption property for an iodine guest $[38,39]$. 

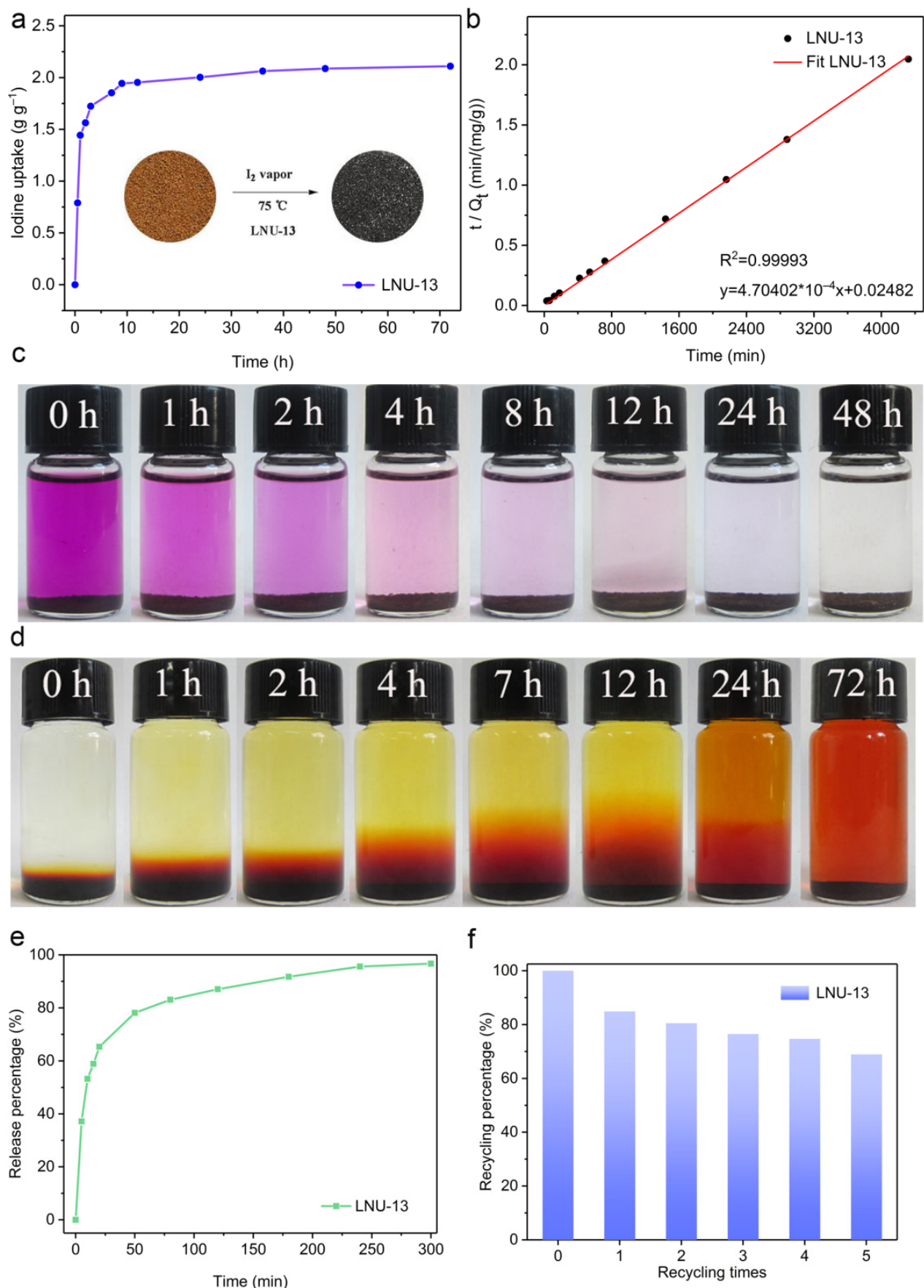

f

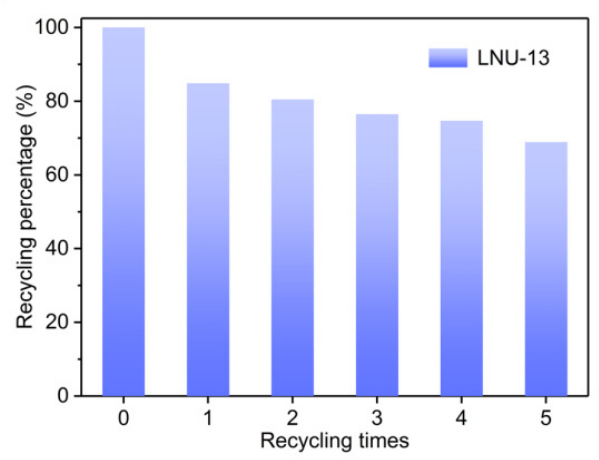

Figure 3. (a) $\mathrm{I}_{2}$ adsorption curve of LNU-13 at $348 \mathrm{~K}$. Inset: the photographs reveal the color change in LNU-13 before and after iodine adsorption; (b) curve-fitting for the $\mathrm{I}_{2}$ adsorption process; (c) photographs showing the iodine-adsorbed process in n-hexane; (d) photographs showing the iodine-released process of LNU-13@ $\mathrm{I}_{2}$ in ethanol; (e) $\mathrm{I}_{2}$ release curve of LNU-13@I $\mathrm{I}_{2}$ at $398 \mathrm{~K}$; (f) recycling experiment of LNU-13. 


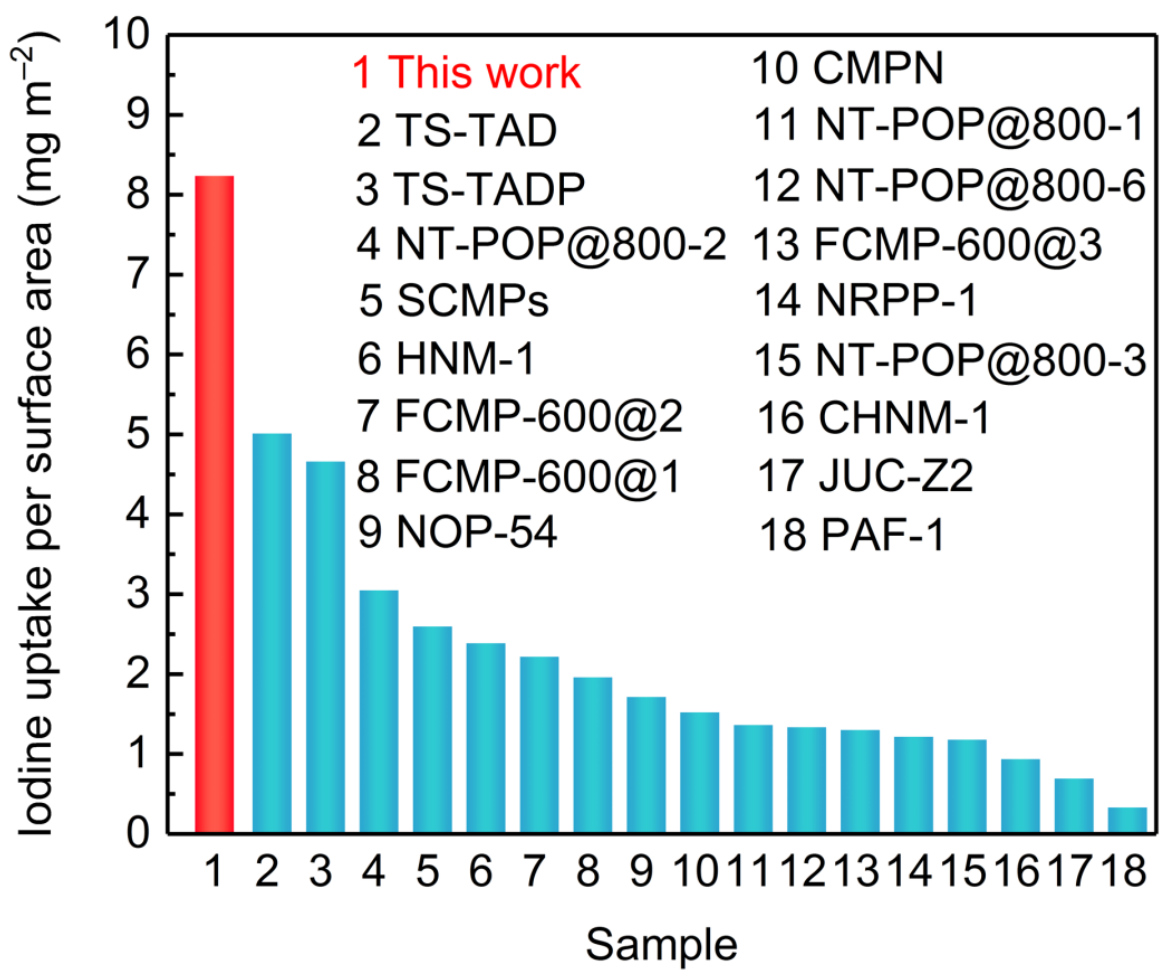

Figure 4. Iodine uptake capacities of different adsorbents.
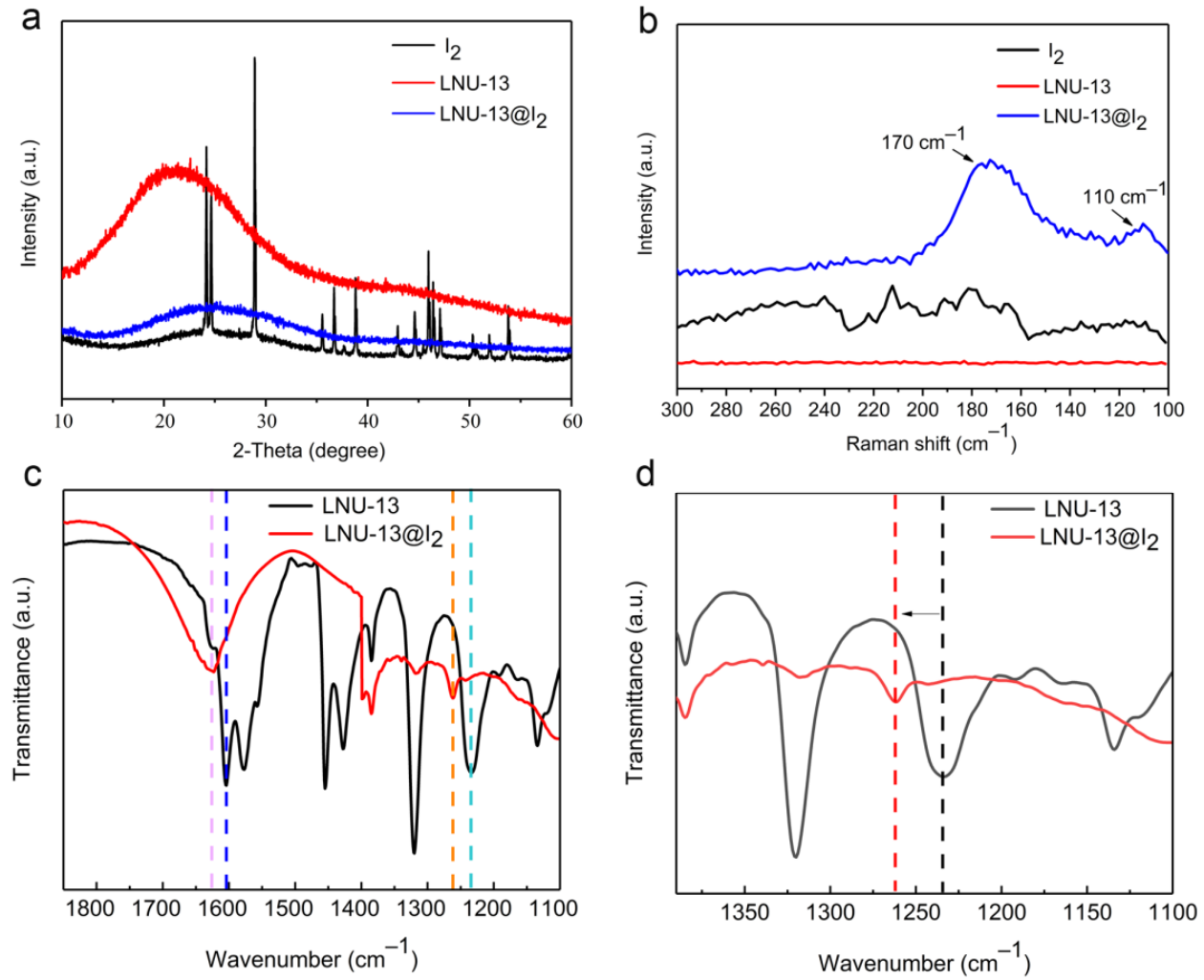

Figure 5. (a) PXRD spectra of $\mathrm{I}_{2}, \mathrm{LNU}-13$, and LNU-13@ $\mathrm{I}_{2}$; (b) Raman spectra of $\mathrm{I}_{2}, \mathrm{LNU}-13$, and LNU-13@I ${ }_{2} ;(\mathbf{c}, \mathbf{d})$ FTIR spectra of LNU-13 and LNU-13@I $\mathrm{I}_{2}$.

In order to evaluate the ability of LNU-13 for the capture of elemental iodine from the solution, LNU-13 powder was immersed into a closed vial containing a pre-prepared iodine elemental $\mathrm{n}$-hexane solution $\left(300 \mathrm{mg} \mathrm{L}^{-1}\right)$. As depicted in Figure $3 \mathrm{c}$, the color of 
the initial solution originated from iodine elemental substance changed from purple to colorless over time; after exposure for $24 \mathrm{~h}$, the n-hexane solution containing both LNU-13 and iodine molecules became transparent and colorless, which proved that LNU-13 powder captured iodine from a $n$-hexane solution.

The recyclability for $\mathrm{I}_{2}$ capture is also a key parameter in practical usage. The iodineloaded LNU-13 powder can be activated by both thermal desorption and solvent elution. The iodine adsorbed in the PAF cavity is easily released in polar organic solvents including methanol and ethanol. After immersion in an ethanol solution for $72 \mathrm{~h}$, the color of the mixture gradually changes from colorless to dark brown, correspondingly, the color of the solid varies from black to brown (Figure 3d). These results manifest that guest iodine is gradually released from the PAF structure into the organic solvent. As shown in Figure 3e, the release efficiency of LNU-13@ $\mathrm{I}_{2}$ is as high as $97 \%$ after the solid is heated in air at $398 \mathrm{~K}$ for $320 \mathrm{~min}$. In addition, the LNU-13 sample withstands multiple adsorption-desorption cycles, and the adsorption capacity reaches $69 \%$ of the initial capacity after five cycles of iodine adsorption (Figure 3f).

\section{Materials and Methods}

\subsection{Materials}

2,7-Dibromocarbazole was purchased from Energy Chemical, Shanghai, China and 1,3,5-triethynylbenzene was received from TCI, Tokyo, Japan. Copper iodide and tetrakis (triphenylphosphine) palladium were obtained from Sigma-Aldrich, St. Louis, MO, USA. Other chemicals and solvents were purchased from commercial suppliers and used without further purification. All reactions were performed under a purified nitrogen atmosphere.

\subsection{Synthesis of LNU-13}

The 2,7-Dibromocarbazole (649 mg, $1.9976 \mathrm{mmol})$, 1,3,5-triethynylbenzene (200 mg, $1.3317 \mathrm{mmol}$ ), tetrakis (triphenylphosphine) palladium (30 mg), and copper (I) iodide $(10 \mathrm{mg})$ were added into a round-bottom flask. The mixture was degassed through a $\mathrm{N}_{2}$ bubbling process for $30 \mathrm{~min}$; after that, $20 \mathrm{~mL}$ of anhydrous $N, N$-dimethylformamide (DMF) and $8 \mathrm{~mL}$ of anhydrous triethylamine (TEA) were added into the system. Then, the reaction mixture was heated to $80{ }^{\circ} \mathrm{C}$ for $72 \mathrm{~h}$ under $\mathrm{N}_{2}$ gas atmosphere. Cooling to room temperature, the precipitate was washed with each DMF, tetrahydrofuran (THF), and acetone solvents for several times to obtain a crude product. Further purification of the product was carried out via Soxhlet extraction with THF, dichloromethane, and methanol in turns for $72 \mathrm{~h}$. The product was dried in a vacuum for $10 \mathrm{~h}$ at $90^{\circ} \mathrm{C}$ to obtain LNU-13.

\subsection{Iodine Adsorption and Release}

\subsubsection{Iodine Adsorption from Volatile Iodine}

The iodine adsorption capacity was analyzed according to the gravimetric measurements. The LNU-13 powder (30.0 mg) was loaded into a small weighing bottle, which was then placed in a closed system at $348 \mathrm{~K}\left(75^{\circ} \mathrm{C}\right)$ and ambient pressure, along with excess non-radioactive solid iodine. After certain time intervals, the bottle was taken out, cooled down to room temperature and weighted, and then loaded back into the vapor of iodine to continue iodine adsorption $[40,41]$. The weight percentage of captured iodine was calculated using the following formula:

$$
\text { Adsorption capacity }=\frac{m_{2}-m_{1}}{m_{1}} \times 100 \%
$$

where $m_{2}$ and $m_{1}$ are the masses of PAF powder after and before iodine intake, respectively.

\subsubsection{Iodine Adsorption from Solution}

To evaluate the adsorption of dissolved iodine in cyclohexane, LNU-13 samples were immersed in n-hexane solution $\left(300 \mathrm{mg} \mathrm{L}^{-1}\right)$ containing iodine for $24 \mathrm{~h}$, the adsorption process of iodine was photographed at selected time intervals. 


\subsubsection{Iodine Desorption in Solution}

Ethanol was used as the extraction solvent to evaluate the reversibility of PAF materials iodine adsorption. Pouring five milliliters of ethanol to five milligrams of iodine-loaded polymer, the release process of iodine was photographed at selected time intervals.

\section{Conclusions}

In summary, a carbazole-based porous aromatic framework was successfully synthesized through a one-step Sonogashira-Hagihara cross-coupling polymerization. Based on the Lewis electron pairing effect, the resulting solid achieved the highest value of iodine uptake per specific surface area. The iodine uptake per specific surface area far surpassed that of silver-containing zeolite, MOFs, and CMPs, etc. Our study firmly demonstrated the important role of electron-rich units in the open architecture for capture and the removal of iodine substance, which opened a gate for the design and synthesis of porous adsorbents for remediation of radioactive iodine to address environmental issues.

Author Contributions: Z.Y., L.X. and N.B. designed and planned the project. B.C. and H.Z. conducted all of the experiments. T.Z. and Y.L. helped to characterize the samples. J.X. and N.L. helped to synthesize the materials. Z.Y. and Y.Y. helped to explain the mechanism. Z.Y., Y.Y. and B.C. analyzed the data and wrote the paper. Z.Y., L.X., N.B. and Y.Y. revised the paper. All authors have read and agreed to the published version of the manuscript.

Funding: This work was supported by the National Natural Science Foundation of China (31972522, 21704037, 21671089), National Key Research and Development Project of China (2018YFC1801200), Major Science and Technology Project of Liaoning Province (2019JH1/10300001), the Scientific Research Fund of Liaoning Provincial Education Department (2020-YKLH-22), LiaoNing Revitalization Talents Program (XLYC2007032), Scientific Research Fund of Liaoning Provincial Education Department (LQN202003).

Institutional Review Board Statement: Not applicable.

Informed Consent Statement: Not applicable.

Data Availability Statement: All data related to this study are presented in this publication.

Acknowledgments: All individuals appreciate the partial support of Liaoning University.

Conflicts of Interest: The authors declare no conflict of interest.

Sample Availability: Samples are not available from the author.

\section{References}

1. Chu, S.; Majumdar, A. Opportunities and challenges for a sustainable energy future. Nature 2012, 488, 294-303. [CrossRef]

2. Hoffert, M.I.; Caldeira, K.; Benford, G.; Criswell, D.R.; Green, C.; Herzog, H.; Jain, A.K.; Kheshgi, H.S.; Lackner, K.S.; Lewis, J.S. Advanced Technology Paths to Global Climate Stability: Energy for a Greenhouse Planet. Science 2002, 298, 981-987. [CrossRef]

3. Ren, F.; Zhu, Z.Q.; Qian, X.; Liang, W.D.; Mu, P.; Sun, H.X.; Liu, J.H.; Li, A. Novel thiophene-beared conjugated microporous polymer honeycomb-liked porous spheres with ultrahigh Iodine uptake. Chem. Commun. 2016, 52, 9797-9800. [CrossRef] [PubMed]

4. Yan, Z.J.; Yuan, Y.; Tian, Y.Y.; Zhang, D.M.; Zhu, G.S. Highly efficient enrichment of volatile iodine by charged porous aromatic frameworks with three sorption sites. Angew. Chem. Int. Ed. 2015, 54, 12733-12737. [CrossRef]

5. Liang, S.Y.; Fan, Z.Y.; Zhang, W.D.; Guo, M.; Cheng, F.Q.; Zhang, M. Controllable growth of $\mathrm{Na}_{2} \mathrm{CO}_{3}$ fibers for mesoporous activated alumina ball modification towards the high-efficiency adsorption of $\mathrm{HCl}$ gas at low temperature. RSC Adv. 2017, 7, 53306-53315. [CrossRef]

6. Lan, Y.S.; Tong, M.M.; Yang, Q.Y.; Zhong, C.L. Computational screening of covalent organic frameworks for the capture of radioactive iodine and methyl iodide. CrystEngComm 2017, 19, 4920-4926. [CrossRef]

7. Lei, Y.; Zhan, Z.S.; Saakes, M.; Weijden, R.D.; Buisman, C.J.N. Electrochemical recovery of phosphorus from acidic cheese wastewater: Feasibility, quality of products, and comparison with chemical precipitation. ACS EST Water 2021, 1, $1002-1013$.

8. Ighaloa, J.O.; Adeniyia, A.G.; Adelodun, A.A. Recent advances on the adsorption of herbicides and pesticides from polluted waters: Performance evaluation via physical attributes. J. Ind. Eng. Chem. 2021, 93, 117-137. [CrossRef]

9. Cui, P.; Jing, X.F.; Yuan, Y.; Zhu, G.S. Synthesis of porous aromatic framework with Friedel-Crafts alkylation reaction for $\mathrm{CO}_{2}$ separation. Chin. Chem. Lett. 2016, 27, 1479-1484. [CrossRef] 
10. Wang, W.; Yuan, Y.; Sun, F.X.; Zhu, G.-S. Targeted synthesis of novel porous aromatic frameworks with selective separation of $\mathrm{CO}_{2} / \mathrm{CH}_{4}$ and $\mathrm{CO}_{2} / \mathrm{N}_{2}$. Chin. Chem. Lett. 2014, 25, 1407-1410. [CrossRef]

11. Rabbani, M.G.; Islamoglu, T.; El-Kaderi, H.M. Benzothiazole- and benzoxazole-linked porous polymers for carbon dioxide storage and separation. J. Mater. Chem. A 2017, 5, 258-265. [CrossRef]

12. Muhammad, R.; Mohanty, P. Cyclophosphazene based hybrid nanoporous materials as superior metal-free adsorbents for gas sorption applications. Langmuir 2018, 34, 2926-2932. [CrossRef]

13. Zhao, Y.B.; Yuan, Y.; Xu, Y.M.; Zheng, G.Y.; Zhang, Q.; Jiang, Y.Q.; Wang, Z.Y.; Bu, N.S.; Xia, L.X.; Yan, Z.J. Fine-regulating ultramicropore of porous carbon via a selfsacrificial template route for high-performance supercapacitors. Nanoscale 2021, 13, 1961-1969. [CrossRef] [PubMed]

14. Yuan, Y.; Zhu, G. Porous aromatic frameworks as a platform for multifunctional applications. ACS Cent. Sci. 2019, 5, 409-418. [CrossRef] [PubMed]

15. Hadi, A.G.; Jawad, K.; Yousif, E.; El-Hiti, G.A.; Alotaibi, M.H.; Ahmed, D.S. Synthesis of telmisartan organotin(IV) complexes and their use as carbon dioxide capture media. Molecules 2019, 24, 1631. [CrossRef]

16. Yuan, Y.; Yang, Y.J.; Zhu, G. Molecularly Imprinted Porous Aromatic Frameworks for Molecular Recognition. ACS Cent. Sci. 2020, 6, 1082-1094. [CrossRef]

17. Singh, G.; Kim, I.Y.; Lakhi, K.S.; Joseph, S.; Srivastava, P.; Naidu, R.; Vinu, A. Heteroatom functionalized activated porous biocarbons and their excellent performance for $\mathrm{CO}_{2}$ capture at high pressure. J. Mater. Chem. A 2017, 5, 21196-21204. [CrossRef]

18. Pelech, I.; Sibera, D.; Staciwa, P.; Narkiewicz, U.; Cormia, R. Pressureless and low-pressure synthesis of microporous carbon spheres applied to $\mathrm{CO}_{2}$ adsorption. Molecules 2020, 25, 5328. [CrossRef]

19. Muhammad, R.; Chaudhary, M.; Mohanty, P. Harnessing electron-rich framework in cyclophosphazene derived hybrid nanoporous materials for organocatalytic C-C bond formation and gas sorption applications. J. $\mathrm{CO}_{2}$ Util. 2018, 25, 302-309. [CrossRef]

20. Maya, E.M.; Valverde-Gonzalez, A.; Iglesias, M. Conversion of $\mathrm{CO}_{2}$ into chloropropene carbonate catalyzed by iron (II) phthalocyanine hypercrosslinked porous organic polymer. Molecules 2020, 25, 4598. [CrossRef]

21. Han, Z.-Y.; Li, H.-K.; Zhu, Q.-Q.; Yuan, R.; He, H. An intriguing electrochemical impedance aptasensor based on a porous organic framework supported silver nanoparticles for ultrasensitively detecting theophylline. Chin. Chem. Lett. 2021. [CrossRef]

22. Yadav, H.; Vinodkumar, M.; Limbachiya, C.; Vinodkumar, P.C.; Mason, N.J. Low energy electron interactions with Iodine molecule (I $\mathrm{I}_{2}$. J. Quant. Spectrosc. Radiat. Transf. 2020, 250, 107035-107045. [CrossRef]

23. Yeager, C.M.; Amachi, S.; Grandbois, R.; Kaplan, D.I.; Xu, C.; Schwehr, K.A.; Santschi, P.H. Microbial Transformation of Iodine: From Radioisotopes to Iodine Deficiency. Adv. Appl. Microbiol. 2017, 101, 83-136.

24. Alizadeh, N.; Dehghanikhah, S. Spectrophotometric study of the charge transfer complexes of 4'-nitrobenzo-15-crown-5 and benzo-15-crown-5 with iodine in nonaqueous solvents. Chin. Chem. Lett. 2011, 22, 587-590. [CrossRef]

25. Hu, K.K.; Huang, W.X.; Su, Y.H.; Hu, R.Z. Simultaneous determination of fluorine and iodine in urine by ion chromatography with electrochemical pretreatment. Chin. Chem. Lett. 2009, 20, 1483-1486. [CrossRef]

26. Xiong, S.H.; Tang, X.; Pan, C.Y.; Li, L.; Tang, J.T.; Yu, G.P. Carbazole-bearing porous organic polymers with mulberry-like morphology for efficient iodine capture. ACS Appl. Mater. Interfaces 2019, 11, 27335-27342. [CrossRef] [PubMed]

27. Dey, D.; Murmu, N.C.; Banerjee, P. Tailor-made synthesis of a melamine-based aminal hydrophobic polymer for selective adsorption of toxic organic pollutants: An initiative towards wastewater purification. RSC Adv. 2019, 9, 7469-7478. [CrossRef]

28. Yang, X.Y.; Chen, L.H.; Li, Y.; Rooke, J.C.; Sanchez, C.; Su, B. Hierarchically porous materials: Synthesis strategies and structure design. Chem. Soc. Rev. 2017, 46, 481-558. [CrossRef] [PubMed]

29. Sun, Q.; Dai, Z.F.; Meng, X.J.; Xiao, F.S. Porous polymer catalysts with hierarchical structures. Chem. Soc. Rev. 2015, 44, 6018-6034. [CrossRef]

30. Shen, D.Z.; Cai, T.T.; Zhu, X.L.; Ma, X.L.; Kong, L.Q.; Kang, Q. Monitoring iodine adsorption onto zeolitic-imidazolate framework8 film using a separated-electrode piezoelectric sensor. Chin. Chem. Lett. 2015, 26, 1022-1025. [CrossRef]

31. Li, G.; Huang, Y.; Lin, J.; Yu, C.; Liu, Z.Y.; Fang, Y.; Xue, Y.M.; Tang, C.C. Effective capture and reversible storage of iodine using foam-like adsorbents consisting of porous boron nitride microfibers. Chem. Eng. J. 2020, 382, 122833-122842. [CrossRef]

32. Ye, F.; Huang, C.; Jiang, X.H.; He, W.; Gao, X.; Ma, L.; Ao, J.X.; Xu, L.; Wang, Z.Q.; Li, Q.G.; et al. Reusable fibrous adsorbent prepared via Co-radiation induced graft polymerization for iodine adsorption. Ecotoxicol. Environ. Saf. 2020, 203, 111021-111028. [CrossRef] [PubMed]

33. Muhammad, R.; Attia, N.F.; Cho, S.; Park, J.; Jung, M.; Chung, J.; Oh, H. Exploitation of surface heterogeneity and textural properties in nanoporous carbon fabrics for efficient iodine capture. Thin Solid Films 2020, 706, 138049-138057. [CrossRef]

34. Chen, X.Y.; Zhang, T.; Han, Y.N.; Chen, Q.; Li, C.P.; Xue, P.C. Multi-responsive fluorescent switches and iodine capture of porous hydrogen-bonded self-assemblies. J. Mater. Chem. C 2021, 9, 9932-9940. [CrossRef]

35. Li, B.; Wang, B.; Huang, X.Y.; Dai, L.; Cui, L.; Li, J.; Jia, X.S.; Li, C.J. Terphen[n]arenes and quaterphen[ $n]$ arenes (n = 3-6): One-pot synthesis, self-assembly into supramolecular gels, and iodine capture. Angew. Chem. Int. Ed. 2019, 58, 3885-3889. [CrossRef]

36. Xu, M.Y.; Wang, T.; Zhou, L.; Hu, D.B. Fluorescent conjugated mesoporous polymers with N,N-diethylpropylamine for the efficient capture and real-time detection of volatile iodine. J. Mater. Chem. A 2020, 8, 1966-1974. [CrossRef] 
37. Hu, X.W.; Wang, H.G.; Faul, C.F.J.; Wen, J.; Wei, Y.; Zhu, M.F.; Liao, Y.Z. A crosslinking alkylation strategy to construct nitrogenenriched tetraphenylmethane-based porous organic polymers as efficient carbon dioxide and iodine adsorbents. Chem. Eng. J. 2020, 382, 12299-12307. [CrossRef]

38. Geng, T.M.; Chen, G.F.; Xia, H.Y.; Zhang, W.Y.; Zhu, Z.M.; Cheng, B.S. Poly\{tris[4-(2-thienyl)phenyl]amine\} and poly[tris(4carbazoyl-9-ylphenyl)amine] conjugated microporous polymers as absorbents for highly efficient iodine adsorption. J. Solid State Chem. 2018, 265, 85-91. [CrossRef]

39. Hassan, A.; Alam, A.; Ansari, M.; Das, N. Hydroxy functionalized triptycene based covalent organic polymers for ultra-high radioactive iodine uptake. Chem. Eng. J. 2022, 427, 130950-130959. [CrossRef]

40. Mehlana, G.; Ramon, G.; Bourne, S.A. A 4-fold interpenetrated diamondoid metal-organic framework with large channels exhibiting solvent sorption properties and high iodine capture. Microporous Mesoporous Mater. 2016, 231, 21-30. [CrossRef]

41. Chen, D.Y.; Fu, Y.; Yu, W.G.; Yu, G.P.; Pan, C.Y. Versatile Adamantane-based porous polymers with enhanced microporosity for efficient $\mathrm{CO}_{2}$ capture and iodine removal. Chem. Eng. J. 2018, 334, 900-906. [CrossRef] 